\title{
The Relationship between the O-antigenic Lipopolysaccharides and Serological Specificity in Strains of Pseudomonas aeruginosa of different O-serotypes
}

\author{
By I. R. CHESTER AND PAULINE M. MEADOW \\ Biochemistry Department, University College London, Gower Street, London WCI $E$ 6BT \\ AND T. L. PITT \\ Cross-Infection Reference Laboratory, Colindale Avenue, London NW9 $5 \mathrm{HT}$
}

(Received 30 March 1973)

\begin{abstract}
SUMMAR Y
The lipopolysaccharides from fifteen strains of Pseudomonas aeruginosa used for serotyping have been isolated and analysed. They all contained heptose, glucose, rhamnose, glucosamine, galactosamine, 2-keto-3-deoxyoctonic acid and alanine. Many of them contained additional sugars and amino compounds, some of which have been shown to be amino sugars. Their composition and structure suggested the existence of a common region of low molecular weight in all the lipopolysaccharides. They could be classified by their chemistry and that of their degradation products into twelve chemogroups, nine of which contained one serotype and three of which contained two serotypes. All the lipopolysaccharides contained the same fatty acids, 3-OH I0:0, 2-OH I2:0, 3-OH I2:0 and I2:0. The isolated lipopolysaccharides reacted with the homologous Habs type antisera. The serological specificity was limited to the high molecular weight regions thought to correspond to side chains.
\end{abstract}

\section{INTRODUCTION}

Over the past few years Pseudomonas aeruginosa has become increasingly important as a source of infection in hospitals. For epidemiological investigations, several typing systems have been developed. Of those based on the specificity of a thermostable antigen, the one most widely used in Europe is that proposed by Habs (1957). This scheme originally differentiated between $\mathrm{I} 2$ serogroups. It has since been extended but there has been no information about its chemical basis.

The serological specificity of the Enterobacteriaceae has been widely studied and strains of Salmonella have been classified on the basis of their O-antigens in the Kauffmann-White scheme (Kauffmann, I966). The specificity resides in the lipopolysaccharides isolated from the bacterial walls, and chemical analysis of these has enabled the chemotype of the lipopolysaccharide to be related to the serological specificity of the organism from which it was obtained (Lüderitz, Staub \& Westphal, I966; Lüderitz, Jann \& Wheat, I968; Lüderitz, Westphal, Staub \& Nikaido, I97I).

Most of the information on the structure of Pseudomonas aeruginosa lipopolysaccharides relates to strains PACI (Fensom \& Meadow, 1970) and NCTC I999 (Fensom \& Gray, 1969; Chester, Gray \& Wilkinson, I972; Drewry, Gray \& Wilkinson, I97I, 1972a, b). The lipopolysaccharides of these strains of $P$. aeruginosa appeared to be similar to those of the Enterobacteriaceae in that they contained components such as heptose, 2-keto-3-deoxyoctonic acid and hydroxy fatty acids. Furthermore, genetic and chemical evidence suggested 
that PACI contained a lipopolysaccharide which was composed of side-chain and core polysaccharides as in the enterobacterial lipopolysaccharides (Fensom \& Meadow, 1970).

The work described here was started to try to establish some chemical basis for the Habs typing system and to determine whether the structures of lipopolysaccharides isolated from various serotypes of Pseudomonas aeruginosa were comparable to those of the Enterobacteriaceae.

\section{METHODS}

Bacterial cultures. The strains of Pseudomonas aeruginosa used in this investigation included type strains for each of the original Habs types I-I 2, and had been obtained from Professor H. Habs, University of Bonn, Germany; types 2 and 5 in the Habs system will be referred to respectively as $2 \mathrm{~A}$ and $5 \mathrm{C}$. The strains $2 \mathrm{~B}$ and $5 \mathrm{D}$ are those described by Veron (I96I) under these designations, and strain I 3 is the 'type II' strain of Sandvik (I960). Other strains used were PACI (Humphreys, Hancock \& Meadow, I972), NCTC I999 and Colindale 9. The latter strain was isolated from clinical material in the Central Public Health Laboratories.

Growth of organisms and isolation of lipopolysaccharide. Each strain was grown overnight (I6 h) in nutrient broth (Oxoid no. 2) at $37^{\circ} \mathrm{C}$ in 51 flasks containing I 1 of media. After harvesting and washing, the bacteria were ruptured using a French press. Walls were purified and treated with $45 \%$ aqueous phenol (Westphal \& Jann, 1965). The resulting aqueous phases were centrifuged to remove contaminating peptidoglycan, dialysed and freeze-dried (Key, Gray \& Wilkinson, I970).

Qualitative analyses. Analytical and preparative paper chromatography were carried out as described by Chester et al. (1972). The following solvent systems were used: A, pyridinebutan-I-ol-water $(4: 6: 3$, by vol.); $\mathrm{B}$, ethyl acetate-pyridine-acetic acid-water $(5: 5: 1: 3$, by vol.); C, acetone-water (I9: I, by vol.); D, butan-I-ol-acetic acid-water ( $5: 1: 2$, by vol.); $\mathrm{E}$, butan-I-ol-ethanol-water-aqueous ammonia (specific gravity 0.880 ) (40:10:49:I, by vol.). Glucose, xylose and rhamnose were identified by paper chromatography using solvent systems A, B and C. Glucosamine phosphate was identified by automatic amino compound analysis and its behaviour in solvent systems B and D as compared with glucosamine-6phosphate. It was indistinguishable from material isolated from hydrolysed lipopolysaccharides of Pseudomonas alcaligenes (Key et al. 1970) and P. aeruginosa 1999 (Chester et al. 1972) and identified by these authors as O-phosphorylglucosamine.

Gas-liquid chromatography of fatty acids was carried out after methylation with $\mathrm{BF}_{3}$ as described by Chester et al. (1972).

Quantitative analyses. Phosphorus was determined by the micro-method of Bartlett (1959) and carbohydrate by the phenol-sulphuric acid reaction (Dubois et al. 1956). D-Glucose was determined with glucose oxidase (blood sugar method, Boehringer Corporation (London) Ltd) after hydrolysis of samples at $100{ }^{\circ} \mathrm{C}(4 \mathrm{~h}, \mathrm{I} \mathrm{N}-\mathrm{HCl})$ followed by neutralization and deionization by ion-exchange resins (Lamkin, Ward \& Walborg, 1966). 2-Keto-3-deoxyoctonic acid, rhamnose and heptose were determined as described by Fensom \& Gray (1969). Amounts of heptose present were calculated as L-glycero-D-mannoheptose using the standard values obtained for this heptose under identical conditions by Osborn (1963). Xylose was determined by the method used for ribose described by Fensom \& Gray (I969).

Amino compound analyses were carried out using a Locarte (London) automatic analyser. Samples were hydrolysed with $6 \cdot \mathrm{I} \mathrm{N}-\mathrm{HCl}$ for $4 \mathrm{~h}$ at $105{ }^{\circ} \mathrm{C}$ and were dried down in vacuo over potassium hydroxide. They were eluted from a column $(0.9 \times 50 \mathrm{~cm})$ of Zeo Karb 225 (graded by Locarte, no. 8) at a temperature of $52{ }^{\circ} \mathrm{C}$ with a flow rate from the column of $0.5 \mathrm{ml} / \mathrm{min}$. Three successive elution buffers were used: (I) 0.1 M-sodium citrate ( $\mathrm{pH} 3.20$, 
$0.2 \mathrm{~N}-\mathrm{Na}^{+}$) for $280 \mathrm{~min}$; (2) $0.1 \mathrm{I}$-sodium citrate $\left(\mathrm{pH}_{4} \cdot 25,0.2 \mathrm{~N}-\mathrm{Na}^{+}\right.$) for $220 \mathrm{~min}$; (3) 0.33 M-sodium citrate ( $\mathrm{pH} 6 \cdot 60, \mathrm{I} \cdot \mathrm{O} \mathrm{N}-\mathrm{Na}^{+}$) for $360 \mathrm{~min}$. Under these conditions glucosamine was eluted after $4 \mathrm{I} 2 \mathrm{~min}$ and galactosamine after $469 \mathrm{~min}$. Eluted amino compounds were detected by reaction of the column effluent with ninhydrin. No attempt was made to correct the values obtained for incomplete release and loss of material during hydrolysis.

Removal of Lipid A. Lipopolysaccharide was hydrolysed with I \% acetic acid in a similar manner to that described by Fensom \& Meadow (I970). The resulting polysaccharide was freeze-dried and fractionated by elution from a column of Sephadex G-75 with pyridineacetate buffer (0.05 M).

Preparation of antisera. Antisera were prepared against the various type strains in essentially the same manner as described by Habs (1957). Cultures were grown on blood agar for $\mathrm{I} 8 \mathrm{~h}$ at $37^{\circ} \mathrm{C}$, harvested with aqueous sodium chloride $(0.85 \%)$, boiled for $\mathrm{I} 50 \mathrm{~min}$ and washed twice with aqueous sodium chloride. The bacteria were suspended to a density of $\mathrm{I} \times 1 \mathrm{IO}^{9}$ organisms/ml as determined using Wellcome opacity tubes (Burroughs Wellcome Ltd) and the suspensions stored at $4{ }^{\circ} \mathrm{C}$. Rabbits were injected intravenously with six increasing doses $(0.25,0.50, \mathrm{I} \cdot 00, \mathrm{I} \cdot 50,2.00$ and $2.00 \mathrm{ml})$, one dose being administered every 2 to 3 days. The rabbits were bled within 2 days of the last dose and exsanguinated 3 to 4 days later. The antisera were sterilized by filtration. In general, the antisera were found to have titres in the range 320 to 1280 against homologous strains in tube-agglutination tests. Cross-reaction was observed in certain cases, thus sera prepared against strains $2 \mathrm{~B}$ and $5 \mathrm{C}$ were absorbed with strain $2 \mathrm{~A}$, serum prepared against strain $2 \mathrm{~A}$ was absorbed with strain $2 \mathrm{~B}$ and serum prepared against strain 7 was absorbed with strain 8 .

Reaction of lipopolysaccharide with antisera. Isolated lipopolysaccharides and fractions obtained after their degradation were tested for reaction with all the antisera. Initially, the capillary precipitin test (Swift, Wilson \& Lancefield, 1943) was applied with undiluted antisera. Any reaction obtained in the latter test was then confirmed with undiluted antisera in the ring precipitin test (Lancefield, 1933) and the double gel diffusion test (Ouchterlony, 1953).

\section{RESULTS}

Chemical analysis of lipopolysaccharides. The lipopolysaccharides from each of the type strains Pseudomonas aeruginosa were isolated and their components identified and estimated as described in Methods. All the lipopolysaccharides contained glucose, rhamnose, heptose and 2-keto-3-deoxyoctonic acid (Table I). In general, these components were present in similar amounts but there were some differences. For example, type 3 lipopolysaccharide contained more and type $2 \mathrm{~A}$ less rhamnose than most of the other lipopolysaccharides; the glucose contents of the types $2 \mathrm{~A}$ and $5 \mathrm{C}$ lipopolysaccharides were unusually high and that of type 9 was unusually low. Other neutral sugars were present in addition to these components. Occasionally, the amounts detected were appreciable, such as mannose in type 3 lipopolysaccharide and xylose in types 7 and 8 lipopolysaccharides. All lipopolysaccharides contained phosphorus in about the same amounts $(3.6$ to $5.6 \%)$. Traces of ethanolamine were detected in lipopolysaccharides from types $4,5 \mathrm{C}, 7,8$, I0, II, I 2 and $\mathrm{I} 3$ and may have been present in all strains.

Several ninhydrin-positive components, some of which were also silver nitrate-positive and could be amino sugars, were detected by paper chromatography of the hydrolysed lipopolysaccharides. Automatic amino compound analysis confirmed that alanine, galactosamine, glucosamine and glucosamine phosphate were present in all the lipopolysaccharides. The presence of glucosamine phosphate in the hydrolysates suggests that at least some of the 
Table I. Sugar composition of lipopolysaccharides of serological type strains of Pseudomonas aeruginosa

\begin{tabular}{|c|c|c|c|c|c|c|c|}
\hline \multirow[b]{2}{*}{$\begin{array}{l}\text { Type } \\
\text { strain }\end{array}$} & \multicolumn{7}{|c|}{ Component $(\%)$} \\
\hline & Glucose & Rhamnose & Heptose* & Xylose & $\begin{array}{l}\text { 2-keto-3- } \\
\text { deoxy- } \\
\text { octonic } \\
\text { acid }\end{array}$ & Galactose & Mannose \\
\hline I & $6 \cdot 6$ & $3 \cdot 0$ & $3 \cdot 8$ & o & $3 \cdot 4$ & 0 & 0 \\
\hline $2 \mathrm{~A}$ & $17 \cdot 0$ & $\mathrm{I} \cdot 7$ & $4 \cdot 0$ & 0 & $4 \cdot 8$ & 0 & Trace \\
\hline $2 \mathrm{~B}$ & IO'I & $2 \cdot 4$ & $4 \cdot I$ & 0 & $4 \cdot 7$ & 0 & Trace \\
\hline 3 & $10 \cdot 8$ & 13.6 & $4 \cdot 4$ & 0 & $3 \cdot 6$ & 0 & + \\
\hline 4 & $13 \cdot 9$ & $5 \cdot 7$ & $3 \cdot 3$ & 0 & $4 \cdot 4$ & 0 & 0 \\
\hline $5 \mathrm{C}$ & $18 \cdot 0$ & 3.8 & $3 \cdot 4$ & 0 & $4 \cdot 0$ & 0 & 0 \\
\hline $5 \mathrm{D}$ & $9 \cdot 3$ & $2 \cdot 6$ & $3 \cdot 2$ & 0 & $4 \cdot 6$ & 0 & Trace \\
\hline 6 & $9 \cdot 0$ & $5 \cdot 3$ & $5 \cdot 4$ & o & $3 \cdot 8$ & 0 & 0 \\
\hline 7 & $9 \cdot 2$ & $3 \cdot 7$ & $5 \cdot 4$ & $2 \cdot 0$ & $3 \cdot 6$ & 0 & 0 \\
\hline 8 & $5 \cdot 9$ & $5 \cdot 6$ & $4 \cdot 4$ & $3 \cdot 9$ & $3 \cdot 7$ & 0 & 0 \\
\hline 9 & $4 \cdot 0$ & $6 \cdot 0$ & $2 \cdot 8$ & 0 & $2 \cdot 8$ & Trace & 0 \\
\hline 10 & $8 \cdot 3$ & $6 \cdot 0$ & $5 \cdot 5$ & 0 & $4^{\circ} \circ$ & 0 & Trace \\
\hline I I & $I I \cdot 2$ & $4 \cdot 3$ & $6 \cdot 2$ & 0 & $4 \cdot 4$ & 0 & 0 \\
\hline 12 & $8 \cdot 6$ & 3.2 & $5 \cdot 6$ & 0 & 4.0 & Trace & Trace \\
\hline 13 & $9 \cdot 2$ & $7 \cdot 2$ & 6.6 & 0 & 4.5 & 0 & Trace \\
\hline
\end{tabular}

glucosamine is linked to phosphorus in the lipopolysaccharides, presumably in the Lipid A. The hydrolysates also contained eight unidentified amino compounds (named in order of elution $\mathrm{UI}-\mathrm{U} 8$ ). The amount of each was calculated on the basis of a colour yield of $\mathrm{I} \cdot 00$ (compared to nor-leucine) when reacted with ninhydrin, and a molecular weight equivalent to that of glucosamine. These values differ slightly from the absolute amounts of material present, but they serve to indicate the relative amounts of the unknown amino compounds in relation to one another in the same lipopolysaccharide, and also in different lipopolysaccharides. The amounts of glucosamine phosphate, glucosamine, alanine and galactosamine present in hydrolysates were similar in most of the lipopolysaccharides but type 3 lipopolysaccharide contained unusually large amounts of glucosamine (Table 2). Lipopolysaccharide of type 9 was unusual in that $U_{3}$ and $U_{4}$ accounted for approximately $20 \%$ of its total.

Unknown amino compounds UI and U2 were eluted from the column at a point where diaminopimelic acid appears, 288 to $295 \mathrm{~min}$ after application of the sample. This diamino acid is a common component of peptidoglycan and its presence in lipopolysaccharide preparations usually indicates a degree of contamination with other wall components. However, neither UI nor U2 had the high absorbance at $440 \mathrm{~nm}$ relative to that at $570 \mathrm{~nm}$ characteristic of diaminopimelic acid and the preparations were not contaminated with other components of the peptidoglycan such as muramic acid. It is unlikely that diaminopimelic acid was present. The remaining unknown amino compounds appeared to be basic in character. $\mathrm{U}_{3}(52 \mathrm{I} \mathrm{min}), \mathrm{U}_{4}(543 \mathrm{~min})$ and $\mathrm{U}_{5}, 6,7$ (558 to $\left.569 \mathrm{~min}\right)$ were all eluted after galactosamine but before ammonia $(642 \mathrm{~min})$. U8 was eluted still later $(788 \mathrm{~min})$ but before arginine $(82 \mathrm{I})$. Compounds $\mathrm{U}_{3}$ to $\mathrm{U}_{7}$ ran very close together and $\mathrm{U}_{5}$, $\mathrm{U} 6$ and $\mathrm{U}_{7}$ were never completely separated from one another. There may therefore be additional components which could be detected using a different buffer system. 


\section{Table 2. Amino compounds in lipopolysaccharides of serological type strains of Pseudomonas aeruginosa}

Samples were hydrolysed for $4 \mathrm{~h}$ at $105^{\circ} \mathrm{C}$ with $6 \cdot \mathrm{I} \mathrm{N}-\mathrm{HCl}$. The results obtained by automatic amino compound analysis are not corrected for destruction of slow release of components during hydrolysis. Unknown compounds were determined as compounds having a colour yield of $\mathrm{I} \cdot 00$ and molecular weight equivalent to glucosamine. UI-U8 are unknown amino compounds.

Component (\%)

\begin{tabular}{|c|c|c|c|c|c|c|c|c|c|c|}
\hline $\begin{array}{l}\text { Type } \\
\text { strain }\end{array}$ & $\begin{array}{l}\text { Glucos- } \\
\text { amine } \\
\text { phosphate }\end{array}$ & $\begin{array}{l}\text { Glucos- } \\
\text { amine }\end{array}$ & $\begin{array}{l}\text { Galactos- } \\
\text { amine }\end{array}$ & Alanine & $\mathrm{UI}_{\mathrm{I}}$ & $\mathrm{U}_{2}$ & $\mathrm{U}_{3}$ & $\mathbf{U}_{4}$ & $\mathrm{U}_{5,6,7}$ & U8 \\
\hline I & $1 \cdot 63$ & $4 \cdot 4 \mathrm{I}$ & $2 \cdot 85$ & $3 \cdot 20$ & 0 & $\mathrm{I} \cdot 65$ & $3 \cdot 43$ & I 57 & $1 \cdot 98$ & 0 \\
\hline $2 \mathrm{~A}$ & $2 \cdot 90$ & $3 \cdot 97$ & $3 \cdot 04$ & $1 \cdot 80$ & 0 & 0 & 0.35 & $0.5 \mathrm{I}$ & Trace & 0 \\
\hline 2B & $I \cdot 5 \mathrm{I}$ & 3.87 & $2 \cdot 28$ & $I \cdot 96$ & o & Trace & $I \cdot 68$ & 0.69 & 0 & 0 \\
\hline 3 & $2 \cdot 04$ & 6.89 & $1 \cdot 92$ & $I \cdot 29$ & 0 & I $\cdot 44$ & $0.2 \mathrm{I}$ & 0.14 & 0 & 0 \\
\hline 4 & $2 \cdot 84$ & $4 \cdot 79$ & $3 \cdot 24$ & $2 \cdot 01$ & 0 & 0 & I 99 & $3 \cdot 88$ & 0 & 0 \\
\hline $5 \mathrm{C}$ & $2 \cdot 50$ & $4 \cdot 77$ & 3.06 & $2 \cdot 03$ & 0 & 0 & 0 & $I \cdot I I I$ & 0 & $I \cdot 24$ \\
\hline $5 \mathrm{D}$ & $I \cdot 67$ & $4 \cdot 29$ & $3 \cdot 21$ & $3 \cdot 42$ & 0 & $I \cdot 26$ & 0 & $\mathrm{I} \cdot 94$ & 0 & 0 \\
\hline 6 & $2 \cdot 25$ & $4 \cdot 55$ & $3 \cdot 15$ & $2 \cdot 23$ & $I \cdot 65$ & $2 \cdot 55$ & 0.93 & 3.53 & $2 \cdot 43$ & 0 \\
\hline 7 & $2 \cdot 34$ & $3 \cdot 71$ & $2 \cdot 17$ & $I \cdot 73$ & 0 & 0 & 0 & $2 \cdot 27$ & 0 & 0 \\
\hline 8 & $\mathrm{I} \cdot 84$ & 3.04 & I 96 & I. 39 & 0 & 0 & 0 & $5 \cdot 73$ & 0 & 0 \\
\hline 9 & $1 \cdot 90$ & $2 \cdot 18$ & $I \cdot 44$ & 1.05 & 0 & 0 & 10.15 & $9 \cdot 96$ & Trace & 0 \\
\hline IO & $2 \cdot 36$ & $3 \cdot 66$ & $2 \cdot 46$ & $\mathrm{I} \cdot 58$ & 0 & $1 \cdot 96$ & 4.60 & $1 \cdot 03$ & 0 & 0 \\
\hline I I & $3 \cdot 30$ & $4 \cdot 25$ & $2 \cdot 60$ & $2 \cdot 18$ & 0 & 0 & 0 & 7.90 & 0 & 0 \\
\hline I 2 & $2 \cdot 57$ & $3 \cdot 76$ & $2 \cdot 28$ & $I \cdot 75$ & 0 & 0 & $2 \cdot 47$ & 0.35 & 0 & 0 \\
\hline I3 & $2 \cdot 61$ & 4.00 & $2 \cdot 68$ & $I \cdot 86$ & 0 & 0.75 & $\mathrm{I} \cdot 68$ & 0.14 & 0.92 & 0 \\
\hline
\end{tabular}

In order to try to identify some of the unknown amino compounds, about $100 \mathrm{mg}$ of type 6 lipopolysaccharide was hydrolysed and examined by paper chromatography in several solvent systems. Separation in solvent B (ethyl acetate-pyridine-acetic acid-water) gave three discrete ninhydrin- and silver nitrate-positive bands with $R$ glucosamine values of $I \cdot 53, I \cdot 35$ and 0.32 respectively. After elution from a preparative chromatogram the three spots were chromatographed in solvents $\mathrm{D}$ and $\mathrm{E}$. The order of the three bands was the same in all three solvents, but the fastest-moving component separated in solvents $\mathrm{D}$ and $\mathrm{E}$ into a major and two minor components. The major component was eluted and shown by automatic amino compound analysis to be identical with $\mathrm{U}_{3}$. The slowest moving amino sugar appeared to be $\mathrm{U}_{2}$, while the material with intermediate $R_{F}$ was $\mathrm{U}_{4}$. All three appeared to be amino sugars and the behaviour of $U_{3}$ and $U_{4}$ was similar to that expected from quinovosamine and fucosamine, but their complete identification will require the isolation of larger amounts of material.

In addition to the amino compounds discussed above, several minor components were detected by automatic amino compound analysis. These had a high absorbance at $440 \mathrm{~nm}$ compared with that at $570 \mathrm{~nm}$ after reaction with ninhydrin. They were eluted in two distinct regions, one just after glucosamine phosphate and the other between galactosamine and $\mathrm{U}_{4}$. There were three acidic materials in all samples studied and they were assumed to be artefacts produced under the conditions used to hydrolyse the samples since they have been found in unrelated protein samples from other bacteria. In contrast, the basic components consisting of one major and one or two minor peaks were not present in all samples and seemed to be associated in particular with lipopolysaccharides of types 3 and 9 . The nature of these components must await further investigation.

All the lipopolysaccharides contained the same fatty acids $(3-\mathrm{OH}$ I2:0, 2-OH I2:0, 3-OH 10:0 and I 2:0) as had been found in other strains of Pseudomonas aeruginosa (Fensom 
Table 3. Arrangement of lipopolysaccharides of serological type strains of Pseudomonas aeruginosa into chemotypes on the basis of their major sugar and amino compound components

Components present in trace amounts have been excluded.

\begin{tabular}{|c|c|c|c|c|c|c|c|c|c|c|}
\hline \multirow{3}{*}{$\begin{array}{l}\text { Sero- } \\
\text { logical } \\
\text { type }\end{array}$} & \multicolumn{9}{|c|}{ Components } & \multirow[b]{3}{*}{ Chemotype } \\
\hline & \multirow{2}{*}{$\begin{array}{c}\text { Common } \\
\text { com- } \\
\text { ponents* }\end{array}$} & \multirow{2}{*}{$\begin{array}{l}\text { Man- } \\
\text { nose }\end{array}$} & \multirow[b]{2}{*}{ Xylose } & \multicolumn{6}{|c|}{ Amino compounds } & \\
\hline & & & & UI & $\mathrm{U}_{2}$ & $\mathrm{U}_{3}$ & $\mathrm{U}_{4}$ & $\mathrm{U}_{5,6,7}$ & U8 & \\
\hline 3 & + & + & . & . & + & + & + & . & . & I \\
\hline $5 \mathrm{C}$ & + & . & . & . & . & . & + & · & + & II \\
\hline 6 & + & . & . & + & + & + & + & + & • & III \\
\hline $5 \mathrm{D}$ & + & . & . & . & + & . & + & . & . & IV \\
\hline IO & + & . & . & . & + & + & + & . & . & V \\
\hline I I & + & . & . & . & . & . & + & . & . & VI \\
\hline $\left.\begin{array}{r}\mathrm{I} \\
\mathrm{I} 3\end{array}\right\}$ & + & . & · & . & + & + & + & + & - & VII \\
\hline $\left.\begin{array}{l}7 \\
8\end{array}\right\}$ & + & . & + & . & . & · & + & . & . & VIIII \\
\hline $\begin{array}{l}2 \mathrm{~A} \\
2 \mathrm{~B}\end{array}$ & & & & & & & & & & \\
\hline $\begin{array}{r}4 \\
9\end{array}$ & + & . & . & . & . & + & + & . & . & IX \\
\hline
\end{tabular}

* Heptose, glucose, rhamnose, 2-keto-3-deoxyoctonic acid, galactosamine, alanine and glucosamine.

+ , Component present.

\& Gray, I969; Hancock, Humphreys \& Meadow, 1969; 1970). Although there were some differences in amounts between the various serotypes they were qualitatively similar.

From these results it appeared that the lipopolysaccharides of Pseudomonas aeruginosa, unlike those of the Enterobacteriaceae, could not readily be differentiated by their neutral sugar composition alone. However, by considering also the amino compounds in the lipopolysaccharides the fifteen lipopolysaccharides could be divided into nine chemogroups (I-IX). Six of these could be distinguished clearly from all the others, two of the other three groups contained only two serotypes, but group IX contained five serotypes (Table 3).

Hydrolysis of polysaccharide from Lipid A. The lipopolysaccharide of Pseudomonas aeruginosa PACI (type 3) can be split into Lipid A and degraded polysaccharide fragments by hydrolysis with I \% acetic acid. The polysaccharide part can then be fractioned into high and low molecular weight materials thought to correspond to side-chain and core regions (Fensom \& Meadow, I970). It seemed possible that we might be able to distinguish between the unresolved serotypes in chemotypes VII, VIII and IX by this treatment. Each of the lipopolysaccharides was treated with $\mathrm{r} \%$ acetic acid as described in Methods. The time needed to cleave the lipid from the polysaccharide varied considerably, lipolysaccharide of type $2 \mathrm{~A}$ being hydrolysed in $30 \mathrm{~min}$ while that of type $\mathrm{I} 3 \mathrm{required}$ treatment for $360 \mathrm{~min}$. Lipopolysaccharides of types 9 and ro could be hydrolysed completely only by adding $\mathrm{HCl}$ to a concentration of $0.01 \mathrm{~N}$ which split off the Lipid A in I to $2 \mathrm{~min}$ (Table 4). Types $2 \mathrm{~A}$ and 9 could therefore be distinguished from each other and from the rest of chemogroup IX. The free polysaccharides were fractionated by elution from a column of Sephadex G-75 and detected by the phenol-sulphuric acid reagent. All the strains contained low molecular weight material of about the same molecular weight (peak L, Fig. I) but the rest of the elution profile varied from one strain to another. The elution profile of the lipopolysaccharide from type $2 \mathrm{~A}$ was the simplest, having apparently no high molecular weight material, while that 


\section{Table 4. Effect of $\mathrm{I} \%$ acetic acid on lipopolysaccharide of serological type strains of Pseudomonas aeruginosa}

The polysaccharide obtained after hydrolysis was fractionated into high and low molecular weight material ( $\mathrm{H}$ and $\mathrm{L}$ ) by elution from a column of Sephadex G-75.

$\begin{array}{cc}\text { Type } & \begin{array}{c}\text { Time taken } \\ \text { for hydrolysis } \\ \text { (min) }\end{array} \\ \text { I } & 240 \\ \text { 2A } & 30 \\ \text { 2B } & 60 \\ 3 & 50 \\ 4 & 55 \\ 5 \mathrm{C} & 85 \\ 5 \mathrm{D} & 210 \\ 6 & 65 \\ 7 & 120 \\ 8 & 135 \\ 9 & \dagger \\ \text { 10 } & \dagger \\ \text { I1 } & 70 \\ \text { I2 } & 95 \\ \text { I3 } & 360\end{array}$

\begin{tabular}{|c|c|}
\hline \multicolumn{2}{|c|}{$\begin{array}{l}\% \text { of high molecular weight } \\
\text { material }(\mathrm{H}) \text { estimated from }\end{array}$} \\
\hline $\begin{array}{c}\text { Elution profile } \\
\text { areas* }\end{array}$ & Dry weight \\
\hline $17 \cdot 3$ & $35 \cdot I$ \\
\hline 0.0 & I $8 \cdot 2$ \\
\hline $8 \cdot 3$ & $26 \cdot 4$ \\
\hline $47 \cdot 9$ & $45 \cdot 7$ \\
\hline $8 \cdot 3$ & $16 \cdot 9$ \\
\hline 0 & $13 \cdot 0$ \\
\hline I3.8 & $28 \cdot 4$ \\
\hline $23 \cdot 3$ & $30 \cdot 0$ \\
\hline 0 & $I \cdot 9$ \\
\hline 0 & 2.9 \\
\hline $379 \div$ & $14.8 t$ \\
\hline $39 \cdot 4$ & $24 \cdot 6$ \\
\hline $13 \cdot 1$ & 12.4 \\
\hline 0.0 & $6 \cdot 0$ \\
\hline $3 I \cdot I$ & $16 \cdot 9$ \\
\hline
\end{tabular}

* Based on neutral sugar content since elution profile was obtained by screening column fractions for colour produced with phenol-sulphuric acid reagent.

$\dagger$ Lipid could not be cleaved by acetic acid alone and hydrochloric acid (0.0I N) was added.

\$ High molecular weight material was degraded and was eluted partly with low molecular weight material.

of type 3 contained at least three high molecular weight peaks $\left(\mathrm{H}_{1}, \mathrm{H}_{2}, \mathrm{H}_{3}\right)$. Between these two extremes type 6 polysaccharide gave one high molecular weight peak $(\mathrm{HI})$ and that from type I gave small amounts of several such peaks $(H)$. Examples of the types of profiles obtained are shown in Fig. I. An estimate of the amount of sugar-containing material in the high molecular weight region $(\mathrm{H})$ was made from the area of these peaks in relation to that of the low molecular weight peaks $\mathrm{L}$. The amount of the high molecular weight material was also determined by weighing after evaporation to dryness (Table 4). The two sets of results do not always agree, as for example in type $2 \mathrm{~A}$, where there were appreciable amounts of high molecular weight material but only trace amounts of neutral sugars. In this strain the side-chain material must contain some components other than neutral sugars and these could include the unknown amino compounds detected in the intact lipopolysaccharides. No high molecular weight material was obtained from type 9. However, some material was eluted from the column just before, and together with, core polysaccharide (L), suggesting that it consisted of degraded high molecular weight material. Presumably this was the result of hydrolysis with hydrochloric acid. Polysaccharides of types 7 and 8 contained no high molecular weight material. Possibly the side chains had been degraded during hydrolysis or they may have been of low molecular weight and were eluted from Sephadex G-75 with the core polysaccharide.

The low molecular weight peaks (L) from each strain contained glucose, heptose and rhamnose indicating a common core. However, variations were obtained in the molar ratios of these components and it is difficult to know whether these are due to degraded side-chain material or to minor variations in core structure. If most of the amino compounds occur in 

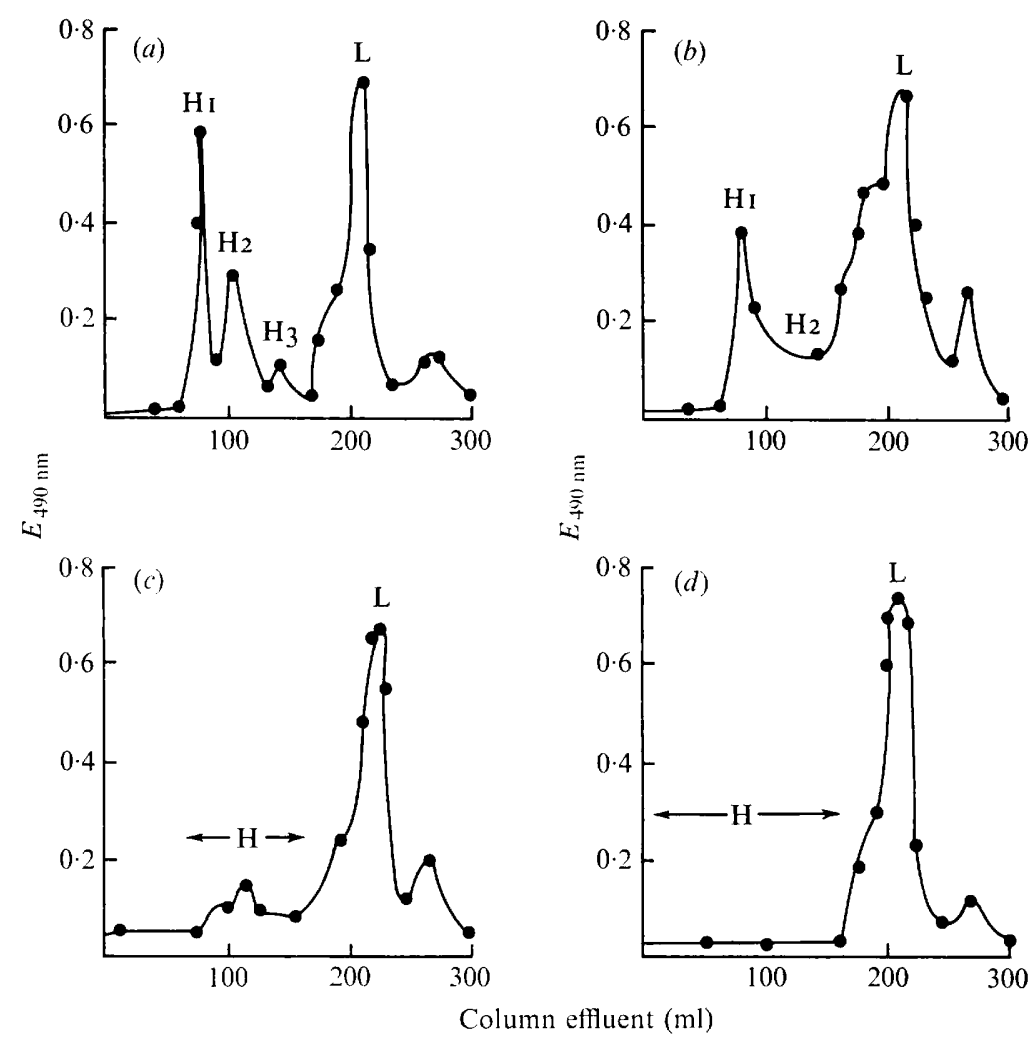

Fig. I. Fractionation of polysaccharide obtained from degradation of lipopolysaccharides with I \% acetic acid. The material was eluted from a column of Sephadex G-75 $(3.0 \times 55 \mathrm{~cm})$ with pyridineacetate buffer $(0.05 \mathrm{M}, \mathrm{pH} 5.4)$. Fractions $(4 \mathrm{ml})$ were analysed for neutral sugar content by the phenol-sulphuric acid method. Lipopolysaccharides were obtained from $(a)$ type $3,(b)$ type 6 , (c) type I and $(d)$ type 2A strains of Pseudomonas aeruginosa.

the side chains their distribution between the high and low molecular weight material might provide some indication. A few strains were therefore analysed in some detail. Low molecular weight polysaccharide contained practically all the alanine and galactosamine present in the eluted polysaccharide whereas the other amino compounds were distributed between high and low molecular weight material (Tables 5 and 6). Where more than one amino compound was present, the distribution of each between the various fractions isolated from one polysaccharide was not necessarily the same. The three high molecular weight peaks in Type Io $\left(\mathrm{HI}_{1}, \mathrm{H}_{2}, \mathrm{H}_{3}\right)$ and the two in type $6\left(\mathrm{HI}_{\mathrm{I}}\right.$ and $\left.\mathrm{H}_{2}\right)$ could be related to each other, but the differences between the peaks from type I3 ( $\mathrm{HI}_{\mathrm{I}}$ and $\mathrm{H}_{2}$ ) suggest at least two distinguishable structures. Although most of the unknown amino compounds were eluted with the side-chain material $(\mathrm{H})$ some were isolated in the lower molecular weight core fractions $(\mathrm{L})$. However, it seems likely that this could be a result of degradation of higher molecular weight material. It is interesting that in lipopolysaccharide of type $2 \mathrm{~A}$ which lacked sugars in the high molecular weight material, the amino compound $\mathrm{U}_{3}$ was found almost exclusively in this material.

Reaction of lipopolysaccharides with antisera. The isolated lipopolysaccharides were tested for reaction against antisera prepared against each of the Habs type strains. Each was 
Table 5. Unknown amino compound composition of high molecular weight material ( $\mathrm{H} \mathrm{I}, \mathrm{H}_{2}$, $\mathrm{H}_{3}$ ) eluted from Sephadex G-75 after hydrolysis of lipopolysaccharides by acetic acid

Fractions were isolated as shown in Fig. 1 and were analysed as described in Methods.

\begin{tabular}{|c|c|c|c|c|c|c|}
\hline \multirow{2}{*}{$\begin{array}{l}\text { Type } \\
\text { strain }\end{array}$} & \multirow{2}{*}{ Fraction } & \multicolumn{5}{|c|}{ Components } \\
\hline & & \multicolumn{5}{|c|}{$\%$ of total present in high and low molecular weight materials } \\
\hline 6 & $\left\{\begin{array}{l}\mathrm{HI} \\
\mathrm{H}_{2}\end{array}\right.$ & $\begin{array}{l}58 \cdot 6 \\
\mathbf{I} \cdot 0\end{array}$ & $\begin{array}{l}60 \cdot 2 \\
1 I \cdot 6\end{array}$ & $\begin{array}{r}6 I \cdot I \\
9 \cdot 0\end{array}$ & $\begin{array}{r}59 \cdot 4 \\
8 \cdot 8\end{array}$ & $\begin{array}{l}56 \cdot 1 \\
13 \cdot 6\end{array}$ \\
\hline IO & $\left\{\begin{array}{l}\mathrm{H}_{1} \\
\mathrm{H}_{2} \\
\mathrm{H}_{3}\end{array}\right.$ & - & $\begin{array}{r}32 \cdot 6 \\
28 \cdot 1 \\
8 \cdot 1\end{array}$ & $\begin{array}{r}26 \cdot 4 \\
26 \cdot 1 \\
8 \cdot 9\end{array}$ & $\begin{array}{l}33 \cdot 9 \\
25 \cdot I \\
I I \cdot 7\end{array}$ & 二 \\
\hline I 3 & $\left\{\begin{array}{l}\mathrm{HI}_{1} \\
\mathrm{H}_{2}\end{array}\right.$ & - & $\begin{array}{r}55 \cdot 2 \\
7 \cdot 2\end{array}$ & $\begin{array}{l}10.3 \\
15.3\end{array}$ & $\begin{array}{c}99 \cdot 0 \\
\text { Trace }\end{array}$ & $\begin{array}{l}49 \cdot 5 \\
\text { Trace }\end{array}$ \\
\hline $\begin{array}{l}2 \mathrm{~A} \\
4\end{array}$ & $\begin{array}{l}\text { HI } \\
\text { HI }\end{array}$ & - & 二 & $\begin{array}{l}93 \cdot 4 \\
24 \cdot 8\end{array}$ & $\begin{array}{l}46 \cdot 6 \\
31 \cdot 5\end{array}$ & - \\
\hline
\end{tabular}

Table 6. Amino compound composition of low molecular weight material $(L)$ eluted from Sephadex $G-75$ after acetic acid hydrolysis of lipopolysaccharides

The low molecular weight material (L) was isolated as shown in Fig. I and analysed as described in Methods. UI-U7 are unknown amino compounds.

\begin{tabular}{|c|c|c|c|c|c|c|c|}
\hline \multirow{3}{*}{$\begin{array}{l}\text { Type } \\
\text { strain }\end{array}$} & \multicolumn{7}{|c|}{ Components } \\
\hline & Alanine & $\begin{array}{l}\text { Galactos- } \\
\text { amine }\end{array}$ & $\mathrm{U}_{\mathrm{I}}$ & U2 & $\mathrm{U}_{3}$ & $\mathrm{U}_{4}$ & $\mathrm{U}_{5}, 6,7$ \\
\hline & \multicolumn{7}{|c|}{$\%$ of total present in high and low molecular weight materials } \\
\hline 6 & 93.0 & $93 \cdot 7$ & $30 \cdot 4$ & $28 \cdot 2$ & $29 \cdot 9$ & $3 I \cdot 8$ & $30 \cdot 3$ \\
\hline IO & 85.4 & $90 \cdot 4$ & - & $3 I \cdot 2$ & 39.4 & $29 \cdot 3$ & - \\
\hline 13 & 94.6 & $>99.9$ & - & 37.6 & $74 \cdot 4$ & Trace & $50 \cdot 5$ \\
\hline $2 \mathrm{~A}$ & $99 \cdot 8$ & $100 \cdot 0$ & - & - & 6.6 & 53.4 & - \\
\hline 4 & $98 \cdot 9$ & $98 \cdot 1$ & - & - & $75 \cdot 2$ & $68 \cdot 5$ & - \\
\hline
\end{tabular}

found to react with its homologous antiserum. The reaction was absolutely specific except with lipopolysaccharides of types $2 \mathrm{~A}, 2 \mathrm{~B}, 5 \mathrm{C}$ and $5 \mathrm{D}$ with which a certain amount of cross reaction was observed.

In order to obtain some indication of the part of the lipopolysaccharide responsible for its antigenicity, the material obtained after fractionation of the acetic acid-degraded lipopolysaccharides was also tested for reaction with the whole range of antisera. The low molecular weight material corresponding to core polysaccharide did not react with any of the antisera. On the other hand, high molecular weight material from all except types 7, 8 and 9 reacted with homologous antisera. Lipopolysaccharides of types 7 and 8 had been shown to lack high molecular weight side chains after acetic acid hydrolysis (Table 4). If there were side chains they might be expected to be eluted with the core fraction, but since this did not react with the antisera there may have been too much degradation for a precipitin reaction. Type 9 lipopolysaccharide was not completely cleaved by acetic acid hydrolysis and had required the addition of hydrochloric acid. The Sephadex elution patterns also showed what 
Table 7. Composition of lipopolysaccharide of Pseudomonas aeruginosa

\begin{tabular}{|c|c|c|c|c|c|c|}
\hline Serological type ... & 6 & 6 & 3 & 3 & $2 B$ & $2 B$ \\
\hline Strain ... & $\begin{array}{l}\text { Type } \\
\text { strain }\end{array}$ & Colindale 9 & $\begin{array}{l}\text { Type } \\
\text { strain }\end{array}$ & PACI & $\begin{array}{l}\text { Type } \\
\text { strain }\end{array}$ & $\begin{array}{l}\text { NCTC } \\
\text { I } 999\end{array}$ \\
\hline Component & \multicolumn{6}{|c|}{$\%$ composition } \\
\hline $\begin{array}{l}\text { Glucosamine } \\
\text { phosphate }\end{array}$ & $2 \cdot 25$ & $I \cdot 85$ & $2 \cdot 04$ & $I \cdot 6 I$ & $I \cdot 5 \mathrm{I}$ & $2 \cdot 11$ \\
\hline Glucosamine & $4 \cdot 55$ & $3.2 \mathrm{I}$ & $6 \cdot 89$ & $6 \cdot 82$ & 3.87 & $3 \cdot 91$ \\
\hline Galactosamine & $3 \cdot 15$ & $I \cdot 9 I$ & $I \cdot 92$ & $I \cdot 54$ & $2 \cdot 28$ & $2 \cdot 43$ \\
\hline Alanine & $2 \cdot 23$ & $I \cdot 48$ & $I \cdot 29$ & $I \cdot I 2$ & $I \cdot 96$ & $1 \cdot 40$ \\
\hline UI & $I \cdot 65$ & $0 \cdot 28$ & 0 & o & 0 & 0 \\
\hline U2 & $2 \cdot 55$ & $2 \cdot 23$ & I 44 & $1 \cdot 84$ & Trace & 0 \\
\hline $\mathrm{U}_{3}$ & 0.93 & $I \cdot 6 I$ & 0.21 & 0.11 & $\mathrm{I} \cdot 68$ & 0.99 \\
\hline $\mathrm{U}_{4}$ & $3 \cdot 53$ & $4 \cdot 67$ & 0.14 & Trace & 0.69 & 0.96 \\
\hline$U_{567}$ & $2 \cdot 43$ & $3 \cdot 7 \mathrm{I}$ & 0 & 0 & 0 & 0 \\
\hline Glucose & $9 \cdot 0$ & 140 & $10 \cdot 8$ & $7 \cdot 4$ & $10 \cdot 1$ & $8 \cdot 7$ \\
\hline Rhamnose & $5 \cdot 3$ & $6 \cdot 4$ & $13 \cdot 6$ & $12 \cdot 8$ & $2 \cdot 4$ & $2 \cdot 3$ \\
\hline Heptose & $5 \cdot 4$ & $3 \cdot 2$ & $4 \cdot 4$ & $4 \cdot 6$ & $4 \cdot 1$ & $4 \cdot 2$ \\
\hline Mannose & 0 & 0 & ++ & ++ & Trace & Trace \\
\hline
\end{tabular}

appeared to be degraded high molecular weight material in addition to the core polysaccharide. Again, this may have been too degraded to react with Habs type 9 antisera. To try to distinguish between these possibilities, lipopolysaccharide was hydrolysed with acetic acid for $150 \mathrm{~min}$ and the resulting material eluted from Sephadex G-75. High molecular weight material was now obtained but did not react with any antisera. This suggests that although the polysaccharide-lipid A linkage was particularly acid resistant in this strain, the antigenic character of the side chains may have been unusually acid labile.

Other lipopolysaccharides. From these results, we were able to distinguish between many of the lipopolysaccharides isolated from the strains used to define the Habs serotyping system on the basis of their chemical composition and structure. Whether the properties we have used to distinguish the various lipopolysaccharides are characteristic for all members of a particular serogroup is uncertain and will not be proven until more strains of Pseudomonas aeruginosa are examined in this way. Preliminary investigations have shown that this is a possibility. Lipopolysaccharides from Pseudomonas aeruginosa NCTC I999 (serotype 2B), PACI (serotype 3) and Colindale 9 (serotype 6) were analysed in the same way as their type strains. There was good agreement both quantitatively and qualitatively between the chemical composition of lipopolysaccharides of the same serogroup (Table 7). Similarly, hydrolysis with acetic acid and subsequent fractionation using Sephadex G-75 gave elution profiles which were very similar for lipopolysaccharides of the same serogroup.

\section{DISCUSSION}

Earlier work on the structure of the lipopolysaccharide of Pseudomonas aeruginosa PACI had suggested that side-chain polysaccharides were attached to a core polysaccharide consisting of glucose, heptose, alanine and galactosamine (Fensom \& Meadow, 1970). More recently (I. R. Chester \& P. M. Meadow, unpublished results), evidence has been obtained that rhamnose is also a component of the core polysaccharide in this strain. In addition, a polysaccharide has been obtained from $P$. aeruginosa 1999 which resembled closely the core polysaccharide of PACI. Detailed analytical studies showed that rhamnose is an integral part 
of the polysaccharide together with glucose, heptose, alanine and galactosamine (Drewry et al. $1972 b$; D. T. Drewry, personal communication).

All the lipopolysaccharides isolated from the type strains used for serotyping contained the same core components, suggesting that Pseudomonas aeruginosa lipopolysaccharides contain a common core polysaccharide as do those of the Enterobacteriaceae. In contrast to the latter, neutral sugars other than those found in the core do not appear to be important in the pseudomonad side chains, only mannose (in type 3) and xylose (in types 7 and 8) being present in significant amounts. Traces of other sugars were detected but their significance is not known. The few results available on lipopolysaccharides of other strains of $P$. aeruginosa seem to confirm the small amounts of side-chain neutral sugars. Ikeda \& Egami (1973) separated lipopolysaccharide from P. aeruginosa PI4 into two fractions after treatment with deoxycholate. The higher molecular weight fraction contained only small amounts of neutral sugars but most of the amino sugars of the intact polysaccharide. We have found similar distribution in fractions obtained from other strains of $P$. aeruginosa after alkali treatment (I. R. Chester \& P. M. Meadow, unpublished). Hanessian, Regan, Watson \& Haskell (I97I) studied the composition of antigenic material extracted with $10 \%$ trichloroacetic acid from seven strains of $P$. aeruginosa. This contained lipopolysaccharide with other material. In addition to rhamnose and glucose, which were present in all antigens, xylose occurred in one antigen together with an unknown sugar. It would be interesting to know the serotype of this strain since our analyses would suggest it would belong to serotype 7 or 8. Arabinose has been detected in lipopolysaccharide of $P$. aeruginosa in trace amounts (Chester et al. 1972). Other species of pseudomonads have been reported to contain fucose and ribose in their lipopolysaccharides or walls (Wilkinson, 1968; 1970).

The molar ratios of the core components were similar in most of the serotypes. In those lipopolysaccharides containing unusually large amounts of core components, the extra amounts may be present in the side chain. Similarly, although glucosamine would be expected to be present in all the lipopolysaccharides since it is considered to be an essential component of lipid A, excess glucosamine could be present in the side-chain polysaccharide as we had found in the lipopolysaccharide isolated from strain PACI (Fensom \& Meadow, 1970). Although $U_{4}$, which may be fucosamine, was present in all the lipopolysaccharides examined, it may not be a component of the core polysaccharide since in type I 3 for example core polysaccharide could be fractionated using Sephadex G-75 and contained none, or very little, of this compound.

One of the most interesting aspects of the analyses of the various lipopolysaccharides was the presence of the unknown amino compounds. Amino sugars have long been recognized as components of enterobacterial lipopolysaccharides (see Ashwell \& Hickman, 1971). Some of these amino sugars are unusual and do not occur commonly. They are thought to be components of the side-chain polysaccharides in Enterobacteriaceae and possibly a similar situation occurs in Pseudomonas aeruginosa. In some of the lipopolysaccharides studied here, the high molecular weight side-chains contain negligible amounts of neutral sugar and the unknown amino compounds were the only components detected. It is possible that other components are present in addition to the unknown amino compounds, as in lipopolysaccharides of strains PACI and NCTC 1999 which contained unidentified nitrogenous material (Fensom \& Gray, 1969; Fensom \& Meadow, 1970). Only two unusual amino sugars, quinovosamine (Suzuki, Suzuki \& Fukasawa, 1970) and fucosamine (Suzuki, 1969, Fensom \& Gray, 1969) have been reported to occur in isolated lipopolysaccharides of $P$. aeruginosa, although unidentified components (Fensom \& Gray 1969; Fensom \& Meadow, 1970) have been reported. Unusual amino sugars have been found in other species of Pseudomonas; these 
include quinovosamine, fucosamine, 3-amino-3,6-dideoxyglucose and 3-amino-3,6-dideoxyD-galactose (Wilkinson, 1970; 1972; Wilkinson \& Carby, I971). Lipopolysaccharide isolated from a strain of Pseudomonas aeruginosa belonging to serogroup 6 has been found to contain valine (S. G. Wilkinson, personal communication). The lipopolysaccharides which we isolated from type strain 6 and Colindale 9 (serotype 6) both contained two unknown amino compounds, UI and U2, which had similar elution properties to valine when subjected to automatic amino compound analysis. One of these (U2) appears to be an amino sugar but UI could correspond to valine.

The antigenic specificity of the isolated lipopolysaccharides was expected by analogy with the Enterobacteriaceae, but had not previously been shown. During the course of this work Adam, Kontrohr \& Horvath (I97I) studied the reaction between lipopolysaccharide isolated from 23 type strains of Lanyi's antigenic scheme and homologous sera and found specific reactions in both precipitation and haemagglutination tests. In the type strains we studied, the serological specificity of the lipopolysaccharides was confined to the high molecular weight polysaccharide fractions obtained after degradation of the isolated lipopolysaccharides with acetic acid. This material contained most of the amino compounds which could be used to distinguish the various types chemically, and it will be interesting to see whether the antigenic specificity can be linked to specific chemical sequences in these side-chain regions, as has been found for some of the Enterobacteriaceae. Preliminary experiments on partially degraded lipopolysaccharides in this laboratory suggest that some at least of the serological specificities may belost on further fractionation of the Pseudomonasaeruginosa polysaccharides.

The lipopolysaccharides studied in this work were isolated from batch cultures grown under identical conditions in the same medium. About half of the strains were grown on more than one occasion with virtually identical results. It appears that even in batch culture the components of the lipopolysaccharides produced under defined conditions are fairly stable and characteristic of that strain, although the composition of lipopolysaccharide in some species has been shown to be altered by growth conditions (Ellwood \& Tempest, 197I) and we have some preliminary evidence which suggests that the lipopolysaccharide composition of Pseudomonas aeruginosa PACI varies with growth conditions. It remains to be seen whether any of the characteristics established here for the lipopolysaccharides of the strains of $P$. aeruginosa used for serotyping will define the chemical basis for their serological reactions.

We are grateful to the Medical Research Council for a project grant which enabled us to undertake this work and to the Royal Society for the gas chromatograph used. We thank Mr P. D. Laverack who carried out the automatic amino compound analysis and Mrs S. Koval for excellent technical assistance. We would also like to thank Dr M. T. Parker for helpful advice and Dr D. T. Drewry and Dr S. G. Wilkinson for allowing us access to their unpublished work.

\section{REFERENCES}

Adam, M. M., Kontrohr, T. \& Horvath, E. (197I). Serological studies on Pseudomonas aeruginosa O group lipopolysaccharides. Acta microbiologica Academiae scientiarum hungaricae 18, 307-317.

Ashwell, G. \& Hickman, J. (I97I). The chemistry of the unique carbohydrates of bacterial lipopoly. saccharides. In Microbial Toxins, vol. Iv, pp. 235-266. Edited by T. Weinbaum, S. Kadis and S. J. Ajl. New York: Academic Press.

Bartlett, G. R. (1959). Phosphorus assay in column chromatography. Journal of Biological Chemistry 234, 466-468.

Chester, I. R., Gray, G. W. \& Wilkinson, S. G. (1972). Further studies of the chemical composition of the lipopolysaccharide of Pseudomonas aeruginosa. Biochemical Journal 126, 395-407. 
Drewry, D. T., Gray, G. W. \& WiLkINSON, S. G. (197I). Release of ethanolamine pyrophosphate during mild acid hydrolysis of the lipopolysaccharide of Pseudomonas aeruginosa. European Journal of Biochemistry 2I, 400-403.

DreWry, D. T., Gray, G. W. \& Wilkinson, S. G. (1972a). Low molecular weight solutes released during mild acid hydrolysis of the lipopolysaccharides of Pseudomonas aeruginosa. Biochemical Journal x30, 289-295.

Drewry, D. T., Gray, G. W. \& Wilkinson, S. G. (1972 $b$ ). Structural studies of a lipopolysaccharide from Pseudomonas aeruginosa. Journal of General Microbiology 73, viii.

Dubois, M., Gilles, K. A., Hamilton, J. K., Rebers, P. A. \& Smith, F. (1956). Colorimetric method for determination of sugars and related substances. Analytical Chemistry 28, 350-356.

Ellwood, D. C. \& TeMPEST, D. W. (1972). Effects of environment on bacterial wall content and composition. In Advances in Microbial Physiology, vol. 7, pp. 83-117. Edited by A. H. Rose and D. W. Tempest. London: Academic Press.

Fensom, A. H. \& Gray, G. W. (1969). The chemical composition of the lipopolysaccharide of Pseudomonas aeruginosa. Biochemical Journal Ir4, I 85-196.

Fensom, A. H. \& Meadow, P. M. (1970). Evidence for two regions in the polysaccharide moiety of the lipopolysaccharide of Pseudomonas aeruginosa 8602. FEBS Letters 9, 81-84.

HABS, I. (1957). Untersuchungen über die O-Antigene von Pseudomonas aeruginosa. Zeitschrift für Hygiene and Infektionskrankheiten 144, $218-228$.

Hancock, I. C., Humphreys, G. O. \& Meadow, P. M. (1969). The hydroxyacids of Pseudomonas aeruginosa 8602. Biochemical Journal 113, $30 \mathrm{P}$.

Hancock, I. C., Humphreys, G. O. \& Meadow, P. M. (1970). Characterisation of the hydroxyacids of Pseudomonas aeruginosa 8602. Biochimica et biophysica acta 202, 389-391.

HANessian, S., Regan, W., WATSON, D. \& HASKell, T. H. (197I). Isolation and characterisation of antigenic components of a new heptavalent Pseudomonas vaccine. Nature New Biology, London 229, 209-210.

HumphreYs, G. O., Hancock, I. C. \& Meadow, P. M. (1972). Synthesis of the hydroxyacids in lipid A of Pseudomonas aeruginosa. Journal of General Microbiology 71, 221-230.

IKrDA, K. \& EgAmI, F. (1973). Lipopolysaccharide of Pseudomonas aeruginosa with special reference to pyocin R receptor activity. Journal of General and Applied Microbiology 19, II5-128.

KaUfFMAnN, F. (1966). The Bacteriology of Enterobacteriaceae. Copenhagen: Munksgaard.

KeY, B. A., GraY, G. W. \& Wilkinson, S. G. (I970). The purification and chemical composition of the lipopolysaccharide of Pseudomonas alcaligenes. Biochemical Journal 120, 559-566.

LAMKIN, W. M., WARD, D. N. \& WALbORG, E. F. (I966). Quantitative determination of neutral monosaccharide residues in glycoproteins and glycopeptides by thin layer densitometry. Analytical Biochemistry I7, 485-494.

LANCEFIELD, R. C. (1933). A serological differentiation of human and other groups of haemolytic streptococci. Journal of Experimental Medicine 57, 57I-595.

LÜDERITZ, O., JANN, K. \& WHEAT, R. (1968). Somatic and capsular antigens of Gram-negative bacteria. In Comprehensive Biochemistry, vol. 26A, pp. 105-228. Edited by M. Florkin and E. H. Stotz. Amsterdam: Elsevier.

LÜDERITZ, O., StAUB, A. M. \& WestPhaL, O. (I966). Immunochemistry of O and R antigens of Salmonella and related Enterobacteriaceae. Bacteriological Reviews 30, 192-255.

LüDeritz, O., WestPhal, O., STAUb, A. M. \& NiKaido, H. (197I). Isolation and chemical and immunological characterisation of bacterial lipopolysaccharides. In Microbial Toxins, vol. IV, pp. 33I-350. Edited by T. Weinbaum, S. Kadis and S. J. Ajl. New York: Academic Press.

OsBorn, M. J. (1963). Studies on the Gram-negative cell wall. I. Evidence for the role of 2-keto-3-deoxyoctonate in the lipopolysaccharide of Salmonella typhimurium. Proceedings of the National Academy of Sciences of the United States of America 50, 499-506.

OUCHTERLONY, O. (1953). Antigen-antibody reactions in gels. Acta pathologica et microbiologica scandinavica 26, 507-515.

SANDVIK, O. (1960). Serological comparison between strains of Pseudomonas aeruginosa from human and animal sources. Acta pathologica et microbiologica scandinavica 48, 56-60.

SuzUKI, N. (1969). Isolation of DL-fucosamine from Pseudomonas aeruginosa NIo. Biochimica et biophysica acta $177,371-373$.

Suzuki, N., Suzuki, A. \& Fukasawa, K. (1970). Distribution of 2-amino sugars in Pseudomonas aeruginosa; isolation of D-quinovosamine from Pseudomonas aeruginosa PI4. Journal of the Japanese Biochemical Society 42, I30-134. 
Swift, H. F., Wilson, A. T. \& Lancefield, R. C. (1943). Typing group A haemolytic streptococci by M precipitin reactions in capillary pipettes. Journal of Experimental Medicine 78, 127-133.

Veron, M. (1961). Sur l'agglutination de Pseudomonas aeruginosa: subdivision des groupes antigèniques $0: 2$ et $0: 5$. Annales de l'Institut Pasteur ror, 456-460.

WeStPhal, O. \& JANN, O. (1965). Bacterial lipopolysaccharides. In Methods in Carbohydrate Chemistry, vol. 5, pp. 83-9I. Edited by R. L. Whistler. New York: Academic Press.

Wilkinson, S. G. (1968). Studies on the cell walls of Pseudomonas species resistant to ethylenediaminetetraacetic acid. Journal of General Microbiology 54, 195-213.

WiLKINson, S. G. (1970). Cell walls of Pseudomonas species sensitive to ethylenediaminetetra-acetic acid. Journal of Bacteriology 104, 1035-1044.

Wilkinson, S. G. (1972). Amino sugars in the wall of Pseudomonas fluorescens. Journal of General Microbiology 70, 365-369.

WiLKINSON, S. G. \& CARBY, K. A. (197I). Amino sugars in the cell walls of Pseudomonas species. Journal of General Microbiology 66, 221-227. 